\title{
Isolation of Rare Cells through their Dielectrophoretic Signature
}

\author{
Alireza Salmanzadeh ${ }^{1,2}$ and Rafael V. Davalos ${ }^{1,2 *}$ \\ ${ }^{1}$ School of Biomedical Engineering and Sciences, Virginia Tech-Wake Forest University, Blacksburg, VA, USA \\ ${ }^{2}$ Department of Engineering Science and Mechanics, Virginia Tech, Blacksburg, VA, USA
}

\begin{abstract}
The isolation of rare cells using their dielectrophoretic signature is becoming a popular tool for medical diagnostics, individualized medicine, and anti-bioterrorism. This unique property varies between cell types due to differences in cell size and structure, including membrane morphology and composition.
\end{abstract}

Keywords: Dielectrophoresis; Biomicrofluidics; Contactless dielectrophoresis; Cancer early diagnosis; Rare cell isolation; Cancer stem cells; Circulating tumor cells; Bioelectrical; Bioelectrics

\section{Introduction}

There are various situations in which it is desirable to separate bioparticles, such as DNA, viruses, bacterial or mammalian cells from background [1]. Here, we focus on the isolation of rare mammalian cells, from cell mixtures or body fluids for cancer detection and individualized medicine using electrophoresis (DEP) [2]. Isolating rare cells is challenging, mostly due to their low number compared to background cells. For example, in screening for circulating tumor cells (CTCs) to detect cancer, there are only a few CTCs per mL of blood, which includes approximately a billion red blood cells and a million white blood cells. Specifically, it has been reported that there are less than 5 CTCs per $7.5 \mathrm{ml}$ blood, detectable using immunomagnetic labeling in patients diagnosed with metastatic breast cancer [3]. Moreover, in some applications, rare cells are similar in size with background cells, which make rare cell isolation difficult.

Existing cell sorting approaches, such as fluorescence activated cell sorting (FACS) [4], magnetic activated cells sorting [5], and chemically functionalized pillar-based microchips [6], have shown promise as techniques that isolate rare cells, based on known receptors expressed on the surface of the membrane. For example, cancer stem cells (CSCs) are a rare population of cancer cells that have the ability to transplant a new tumor from an existing one. CSCs are thought to be responsible for the metastatic properties of tumors. In the case of pancreatic cancer, less than $1 \%$ of cancer cells expressed positive to specific biomarkers and showed significantly high tumorigenic potential, indicating they are CSCs [7]. Although a powerful technique, biomarker-based methods rely upon surface marker expression labeling, which is timeconsuming, and requires special training to implement. The use of biomarkers also requires a prior knowledge, which is not yet available for all cell types. Moreover, irreversible binding of particles to the cell membrane can permanently disturb the functionality of the cell during isolation, making it difficult to do post-studies [8].

Dielectrophoresis (DEP) is an alternative, noninvasive technique that eliminates extensive sample preparation (no antibody labeling, one needs only to prepare a single sample) and provides a high selectivity for separating rare cells. DEP is the motion of a polarizable particle in a suspending medium due to the presence of a non-uniform electric field [9]. As opposed to other techniques that rely on information at the membrane surface, DEP can noninvasively sort populations through differences within the interior of cells, as well as their exterior. DEP has been used for the isolation of several rare cell types including separation of human breast cancer cells [10-16], human leukemia cells [17], cervical carcinoma cells [18], and malaria-infected cells [19] from blood, HL-60 cells from peripheral blood mononuclear cells [20], human breast cancer cells from normal T-lymphocytes and from CD34+ hematopoietic stem cells [21,22], enrichment of CD34+ stem cells from bone marrow and peripheral blood [23], and from peripheral blood stem cell harvests [24], separation of neuroblastoma cells from glioma cells [25], colorectal cancer cells from normal epithelial cells [26], osteoblast-like cells from a heterogeneous population [27], and putative stem cell population from adipose tissue derived cell suspension [28]. Cell isolation has been done through both batch separation [11-14,16-28], in which the rare cells population is trapped due to positive DEP force, while the background cells pass through the microdevice without trapping, and continuous separation [10], in which rare cells continuously separate from background cells.

In conventional DEP techniques, metallic microelectrodes with various geometries, such as interdigitated [11,13,14,20-22,24,28], castellated [12,17,23,29], oblique [10], spiral [19], circular [18,25], ring shape [27], and wedge shape [26], are patterned on a microfluidic device using conventional lithography techniques. Our group developed a DEP-based technology known as contactless dielectrophoresis (cDEP), which replaces metallic electrodes by fluidic electrode channels, filled with a high conductivity fluid [30,31]. Our approach with cDEP capitalizes on the sensitivity of traditional DEP, while eliminating challenges such as bubble formation, electrode delamination, expensive fabrication, and electrode-sample contamination. The absence of electrochemical contamination makes cDEP an ideal "isolate-andculture" platform to investigate the biological processes of a target cell type, especially rare cells, in a sterilized environment. cDEP has been used to isolate prostate CSCs from normal cancer cells [32], cancer cells from blood cells $[15,16]$, live cells from dead cells [33], and different stages of breast cancer cell lines [34].

In general, differences in dielectric properties of cells come from differences in their size, viability, membrane integrity and morphology,

*Corresponding author: Rafael V. Davalos, Bioelectromechanical Systems Lab, Virginia Tech-Wake Forest School of Biomedical Engineering and Sciences, Virginia Tech, 329 ICTAS Building, (MC0298), Stranger Street, Blacksburg, VA 24061, USA, Tel: +1-540-231-1979; Fax: +1-540-541-8320; E-mail: davalos@vt.edu

Received December 10, 2012; Accepted December 11, 2012; Published December 14, 2012

Citation: Salmanzadeh A, Davalos RV (2013) Isolation of Rare Cells through their Dielectrophoretic Signature. J Membra Sci Technol 3: e112. doi:10.4172/21559589.1000e112

Copyright: (c) 2013 Salmanzadeh A, et al. This is an open-access article distributed under the terms of the Creative Commons Attribution License, which permits unrestricted use, distribution, and reproduction in any medium, provided the original author and source are credited. 
surface protrusions, fine surface features, cytoskeleton structure, and internal composition, such as nucleus to cytoplasm (N/C) ratio [35]. The cell membrane specifically acts like a dielectric between two conducting media. Similar to a capacitor, the specific capacitance of a cell depends on the cell membrane's surface. Smoother cells have lower specific membrane capacitance, $C_{m e m}$, in contrast to cells which have complexities on their membrane such as protrusions, blebs, folding, and microvilli [36]. The $C_{m e m}$ is reduced if there is an increase in the membrane thickness or change in the intramembrane components, which affects the cell polarizability. Interfacial polarization happens due to the movement of positive and negative charges towards the cell sides facing the electrodes, depending on the location of electrodes, and causes forming aggregation of interfacial charges [37]. The interfacial polarization of a membrane surface can be affected by nucleus, endoplasmic reticulum, and mitochondria, as well as cell insulating bodies and structures, such as protein cytoskeleton and lipid membranes [35]. These characteristics have enabled researchers to isolate cells by exploiting differences in their membrane properties, such as membrane protrusions [38] and membrane conductivity [39], as well as the membrane skeleton $[38,40]$.

Here, we present some of the important applications of DEP for enriching and isolating rare cells.

\section{Cancer Cells from Blood Cells}

Isolating cancer cells from blood cells is essential in early cancer detection and monitoring therapeutic outcomes [41]. There are several differences in surface morphology and size of cancer cells and blood cells, which make it possible to isolate them utilizing DEP [10-14,1618]. For example, using a membrane-specific area parameter, $\varphi$, one can quantify subtle variances between cells due to differences in membrane morphology [13]. $\varphi$ is the ratio of the actual membrane area to the membrane area that would be required to cover a smooth cell with the same radius, and can be used to quantify the amount of surface foldings and protrusions, as well as features such as microvilli, villi, ruffles, ridges, and blebs [13], on the membrane. A smooth cell has a membrane capacitance of $9 \mathrm{mF} / \mathrm{m}^{2}$ [42]. For normal cells, such as T-lymphocytes, $\varphi$ has been reported to be close to 1 , however for cancerous cells having more surface protrusions, $\varphi$ can be up to around 4 times higher [43]. DEP can also be combined with other cell sorting techniques, such as multi-orifice flow fractionation (MOFF) [10], to isolate cancer cells from blood cells, by taking advantage of higher throughput of MOFF and higher sensitivity of DEP [10].

\section{Different Stages of Cancer Cells}

It has also been demonstrated that cancerous and normal cells have different electrical properties. Oral squamous cell carcinomas have distinctly different electrical properties than more normal keratinocyte populations [44], and non-cancer-derived oral epithelial cells [45]. In another study, it was shown that normal, pre-cancerous, and cancerous oral keratinocytes have distinct electrical properties [46]. Additionally, transformed and non-transformed rat kidney cells [47], malignant human breast cancer epithelial cells and benign breast epithelial cells $[34,48]$, and healthy and infected erythrocytes have been reported to have different electrical signature [49]. We demonstrated that different stages of breast cancer cell lines can be sorted based on cells dielectric properties [34]. We also showed that $C_{\text {mem }}$ increases in mouse ovarian surface epithelial (MOSE) cells as the stage of malignancy advanced from $15.39 \pm 1.54 \mathrm{mF} / \mathrm{m}^{2}$ for a non-malignant benign stage to $26.42 \pm$ $1.22 \mathrm{mF} / \mathrm{m}^{2}$ for the late, aggressive stage [50]. These differences are the result of morphological differences due to changes in the membrane capacitance, associated with the complexity in the surface morphology, specifically, the density of complex features and cytoskeleton structure.

\section{Stem Cells and Non-stem Cells}

Stem cells are rare cell populations with the ability of self-renewal, as well as generating mature tissue cells through differentiation. Isolating, characterizing, and manipulating these cells have a wide range of applications, including regenerative medicine and cancer treatment. It has been shown that dielectric properties of stem cells are different from differentiated cells [51]. Using DEP, the progenitor cells were isolated from the stromal vascular fraction, which includes cell debris, erythrocytes, and nucleated cells, based on differences in their density, morphology, and size [52]. Moreover, it has been reported that the specific membrane capacitance of breast cancer cells and hematopoietic CD34+ stem cells are different, $23.0 \pm 7.1$ and $10.2 \pm 1.5$ $\mathrm{mF} / \mathrm{m}^{2}$, respectively, and these cells can be isolated accordingly, using dielectrophoretic field-flow-fractionation (DEP-FFF) [22].

\section{Cancer Stem Cells and Normal Cancer Cells}

CSCs can be considered as the most relevant cancer therapeutic target, and their isolation is the first step towards understanding their role in the pathogenesis and progression of cancer to improve specific cancer therapies [53]. Up until recently, no one has studied whether there are bioelectrical differences between CSCs and their counterpart. Our group showed that prostate CSCs have different dielectric properties in comparison to non-CSCs, which can be used for enrichment [32].

Stage of differentiation changes the cells protein cytoskeleton, which consequently changes the mechanical and electrical properties of cells at different stages of differentiation [35]. As an example, the differentiation of the erythroleukaemia cells changes the cell surface characteristics of the surface from having numerous microvilli and filopodia to appearing smooth and discoid, which are characteristics of mature cells [40]. Differentiation also increases the integrity of the spectrin in cytoskeleton and increases structural protein content of the membrane, causing a decrease in the membrane leakage and membrane fluidity [40].

Cells' organelles, e.g. endoplasmic reticulum, nucleus, and mitochondria, change during differentiation of cells and can affect their DEP properties. As an example, differentiation, transformation, and tumorigenicity of cells make a significant change in mitochondrial membrane potential [54]. Carcinoma cells have higher mitochondrial membrane potential than normal cells [55-57]. Based on their mitochondrial membrane potential, cells can be sorted as CSC $>$ cancer cells $>$ normal epithelial cells [54]. Moreover, N/C ratio decreases by cell differentiation and maturity [8], and changes the effective conductivity and permittivity of cells. For instance, limbal epithelial stem cells have a higher N/C ratio $(=0.82[58])$ than peripheral corneal epithelial cells (=0.17 [59]), [8]. Human embryonic stem (hES) cells have typically higher N/C ratio than ordinary somatic cells, which affects their dielectric properties and consequently, can be used to separate these cells.

In summary, the differences in dielectric properties of cells which stem from dissimilarities in cells size, morphology, nucleus/cytoplasm ratio, nucleic acid content, surface charge, and charged cytoplasmic molecules, can be used not only to monitor changes of cells, but also to electrically isolate rare cells from biosamples. Utilizing DEP eliminates the need of labeling cells through their membrane proteins, which saves time and expense. Cells can be used after DEP isolation for 
Citation: Salmanzadeh A, Davalos RV (2013) Isolation of Rare Cells through their Dielectrophoretic Signature. J Membra Sci Technol 3: e112. doi:10.4172/2155-9589.1000e112

culturing and molecular analysis. This has crucial applications, such as early cancer detection, performance monitoring of cancer therapy, regenerative medicine, and cell characterization for individualized medicine.

\section{References}

1. Smith JP, Barbati AC, Santana SM, Gleghorn JP, Kirby BJ (2012) Microfluidic transport in microdevices for rare cell capture. Electrophoresis 33: 3133-3142.

2. Anderson JE, Hansen LL, Mooren FC, Post M, Hug H, et al. (2006) Methods and biomarkers for the diagnosis and prognosis of cancer and other diseases: towards personalized medicine. Drug Resist Updat 9: 198-210.

3. Hayes DF, Cristofanilli M, Budd GT, Ellis MJ, Stopeck A, et al. (2006) Circulating tumor cells at each follow-up time point during therapy of metastatic breas cancer patients predict progression-free and overall survival. Clin Cancer Res 12: $4218-4224$

4. Lostumbo A, Mehta D, Setty S, Nunez R (2006) Flow cytometry: a new approach for the molecular profiling of breast cancer. Exp Mol Pathol 80: 46-53.

5. Kato K, Radbruch A (1993) Isolation and characterization of CD34+ hematopoietic stem cells from human peripheral blood by high-gradient magnetic cell sorting. Cytometry 14: 384-392.

6. Nagrath S, Sequist LV, Maheswaran S, Bell DW, Irimia D, et al. (2007) Isolation of rare circulating tumour cells in cancer patients by microchip technology. Nature 450: 1235-1239.

7. Li C, Heidt DG, Dalerba P, Burant CF, Zhang L, et al. (2007) Identification of pancreatic cancer stem cells. Cancer Res 67: 1030-1037.

8. Pethig R, Menachery A, Pells S, De Sousa P (2010) Dielectrophoresis: a review of applications for stem cell research. J Biomed Biotechnol 2010:182581.

9. Pohl HA (1978) Dielectrophoresis. Cambridge University Press, UK.

10. Moon HS, Kwon K, Kim SI, Han H, Sohn J, et al. (2011) Continuous separation of breast cancer cells from blood samples using multi-orifice flow fractionation (MOFF) and dielectrophoresis (DEP). Lab Chip 11: 1118-1125.

11. Yang J, Huang Y, Wang XB, Becker FF, Gascoyne PR (1999) Cell separation on microfabricated electrodes using dielectrophoretic/gravitational field-flow fractionation. Anal Chem 71: 911-918.

12. Becker FF, Wang XB, Huang Y, Pethig R, Vykoukal J, et al. (1995) Separation of human breast cancer cells from blood by differential dielectric affinity. Proc Natl Acad Sci U S A 92: 860-864.

13. Gascoyne PR, Wang XB, Haung Y, Becker FF (1997) Dielectrophoretic Separation of Cancer Cells from Blood. IEEE Trans Ind Appl 33: 670-678.

14. Gascoyne PR, Noshari J, Anderson TJ, Becker FF (2009) Isolation of rare cells from cell mixtures by dielectrophoresis. Electrophoresis 30: 1388-1398.

15. Sano MB, Caldwell JL, Davalos RV (2011) Modeling and development of a low frequency contactless dielectrophoresis (cDEP) platform to sort cancer cells from dilute whole blood samples. Biosens Bioelectron 30: 13-20.

16. Salmanzadeh A, Sano MB, Shafiee H, Stremler MA, Davalos RV (2012) Isolation of rare cancer cells from blood cells using dielectrophoresis. EMBC2012 San Diego, CA, USA.

17. Becker FF, Wang XB, Huang Y, Pethig R, Vykoukal J, et al. (1994) The removal of human leukaemia cells from blood using interdigitated microeletrodes. $J$ Phys D Appl Phys 27: 2659-2662.

18. Cheng J, Sheldon EL, Wu L, Heller MJ, O'Connell JP (1998) Isolation of cultured cervical carcinoma cells mixed with peripheral blood cells on a bioelectronic chip. Anal Chem 70: 2321-2326.

19. Gascoyne P, Mahidol C, Ruchirawat M, Satayavivad J, Watcharasit P, et al. (2002) Microsample preparation by dielectrophoresis: isolation of malaria. Lab Chip 2: 70-75.

20. Huang Y, Wang XB, Becker FF, Gascoyne PR (1997) Introducing dielectrophoresis as a new force field for field-flow fractionation. Biophys $\mathrm{J} 73$ : 1118-1129.

21. Wang XB, Yang J, Huang Y, Vykoukal J, Becker FF, et al. (2000) Cell separation by dielectrophoretic field-flow-fractionation. Anal Chem 72: 832-839.

22. Huang Y, Yang J, Wang XB, Becker FF, Gascoyne PR (1999) The remova of human breast cancer cells from hematopoietic CD34+ stem cells by dielectrophoretic field-flow-fractionation. J Hematother Stem Cell Res 8: 481 490.

23. Talary MS, Mills KI, Hoy T, Burnett AK, Pethig R (1995) Dielectrophoretic separation and enrichment of CD34+ cell subpopulation from bone marrow and peripheral blood stem cells. Med Biol Eng Comput 33: 235-237.

24. Stephens M, Talary MS, Pethig R, Burnett AK, Mills KI (1996) The dielectrophoresis enrichment of CD34+ cells from peripheral blood stem cel harvests. Bone Marrow Transplant 18: 777-782.

25. Huang Y, Joo S, Duhon M, Heller M, Wallace B, et al. (2002) Dielectrophoretic cell separation and gene expression profiling on microelectronic chip arrays. Anal Chem 74: 3362-3371.

26. Yang F, Yang $X$, Jiang $H$, Bulkhaults $P$, Wood $P$, et al. (2010) Dielectrophoretic separation of colorectal cancer cells. Biomicrofluidics 4: 13204

27. Thomas RS, Mitchell PD, Oreffo RO, Morgan H (2010) Trapping single human osteoblast-like cells from a heterogeneous population using a dielectrophoretic microfluidic device. Biomicrofluidics 4

28. Vykoukal J, Vykoukal DM, Freyberg S, Alt EU, Gascoyne PR (2008) Enrichmen of putative stem cells from adipose tissue using dielectrophoretic field-flow fractionation. Lab Chip 8: 1386-1393.

29. Sabuncu AC, Liu JA, Beebe SJ, Beskok A (2010) Dielectrophoretic separation of mouse melanoma clones. Biomicrofluidics 4.

30. Shafiee H, Caldwell JL, Sano MB, Davalos RV (2009) Contactless dielectrophoresis: a new technique for cell manipulation. Biomed Microdevices 11: 997-1006.

31. Salmanzadeh A, Shafiee H, Davalos RV, Stremler MA (2011) Microfluidic mixing using contactless dielectrophoresis. Electrophoresis 32: 2569-2578.

32. Salmanzadeh A, Romero L, Shafiee H, Gallo-Villanueva RC, Stremler, et al. (2011) Isolation of prostate tumor initiating cells (TICs) through their dielectrophoretic signature. Lab Chip 12: 182-189.

33. Shafiee H, Sano MB, Henslee EA, Caldwell JL, Davalos RV, et al. (2010) Selective isolation of live/dead cells using contactless dielectrophoresis (cDEP). Lab Chip 10: 438-445.

34. Henslee EA, Sano MB, Rojas AD, Schmelz EM, Davalos RV (2011) Selective concentration of human cancer cells using contactless dielectrophoresis. Electrophoresis 32: 2523-2529.

35. Pethig R (2007) Cell Physiometry Tools based on Dielectrophoresis. In BioMEMS and Biomedical Nanotechnology, SpringerLink 103-126.

36. Pethig R (2010) Review article-dielectrophoresis: status of the theory, technology, and applications. Biomicrofluidics 4.

37. Goater AD, Pethig R (1998) Electrorotation and dielectrophoresis. Parasitology 117: S177-S189.

38. Wang XB, Huang Y, Gascoyne PR, Becker FF, Hölzel R, et al. (1994) Changes in Friend murine erythroleukaemia cell membranes during induced differentiation determined by electrorotation. Biochim Biophys Acta 1193: 330344

39. Burt JP, Pethig R, Gascoyne PR, Becker FF (1990) Dielectrophoretic characterisation of Friend murine erythroleukaemic cells as a measure of induced differentiation. Biochim Biophys Acta 1034: 93-101.

40. Gascoyne PR, Pethig R, Burt JP, Becker FF (1993) Membrane changes accompanying the induced differentiation of Friend murine erythroleukemia cells studied by dielectrophoresis. Biochim Biophys Acta 1149: 119-126.

41. Yu M, Stott S, Toner M, Maheswaran S, Haber DA (2011) Circulating tumo cells: approaches to isolation and characterization. J Cell Biol 192: 373-382.

42. Arnold WM, Zimmermann U (1982) Rotation of an isolated cell in a rotating electric field. Naturwissenschaften 69: 297-298.

43. Gascoyne PR, Shim S, Noshari J, Becker FF, Stemke-Hale K (2012) Correlations between the dielectric properties and exterior morphology of cells revealed by dielectrophoretic field-flow fractionation. Electrophoresis.

44. Broche LM, Bhadal N, Lewis MP, Porter S, Hughes MP, et al. (2007) Early detection of oral cancer - Is dielectrophoresis the answer? Oral Oncol 43:199 203

45. Yang L, Arias LR, Lane TS, Yancey MD, Mamouni J (2011) Real-time electrica impedance-based measurement to distinguish oral cancer cells and noncancer oral epithelial cells. Anal Bioanal Chem 399: 1823-1833. 
Citation: Salmanzadeh A, Davalos RV (2013) Isolation of Rare Cells through their Dielectrophoretic Signature. J Membra Sci Technol 3: e112. doi:10.4172/2155-9589.1000e112

46. Mulhall HJ, Labeed FH, Kazmi B, Costea DE, Hughes MP, et al. (2011) Cancer, pre-cancer and normal oral cells distinguished by dielectrophoresis. Anal Bioanal Chem 401: 2455-2463.

47. Huang Y, Wang XB, Becker FF, Gascoyne PR (1996) Membrane changes associated with the temperature-sensitive P85gag-mos-dependent transformation of rat kidney cells as determined by dielectrophoresis and electrorotation. Biochim Biophys Acta 1282: 76-84.

48. An J, Lee J, Lee SH, Park J, Kim B (2009) Separation of malignant human breast cancer epithelial cells from healthy epithelial cells using an advanced dielectrophoresis-activated cell sorter (DACS). Anal Bioanal Chem 394: 801 809.

49. Braschler T, Demierre N, Nascimento E, Silva T, Oliva AG, et al. (2008) Continuous separation of cells by balanced dielectrophoretic forces at multiple frequencies. Lab Chip 8: 280-286.

50. Salmanzadeh A, Kittur H, Sano MB, Roberts PC, Schmelz EM, et al (2012) Dielectrophoretic differentiation of mouse ovarian surface epithelia cells, macrophages, and fibroblasts using contactless dielectrophoresis. Biomicrofluidics. 6: 024104-024113.

51. Flanagan LA, Lu J, Wang L, Marchenko SA, Jeon NL, et al. (2008) Unique dielectric properties distinguish stem cells and their differentiated progeny. Stem Cells 26: 656-665.
52. Vykoukal J, Vykoukal DM, Freyberg S, Alt EU, Gascoyne PR (2008) Enrichment of putative stem cells from adipose tissue using dielectrophoretic field-flow fractionation. Lab Chip 8: 1386-1393.

53. Reya T, Morrison SJ, Clarke MF, Weissman IL (2001) Stem cells, cancer, and cancer stem cells. Nature 414: 105-111.

54. Ye XQ, Wang GH, Huang GJ, Bian XW, Qian GS, et al. (2011) Heterogeneity of mitochondrial membrane potential: a novel tool to isolate and identify cancer stem cells from a tumor mass? Stem Cell Rev 7: 153-160.

55. Chen LB (1988) Mitochondrial membrane potential in living cells. Annu Rev Cell Biol 4: 155-181.

56. Kroemer G, Pouyssegur J (2008) Tumor cell metabolism: cancer's Achilles' heel. Cancer Cell 13: 472-482.

57. Hockenbery DM (2002) A mitochondrial Achilles' heel in cancer? Cancer Cell 2: $1-2$.

58. Turgeon ML (2004) Clinical Hematology: Theory and Procedures. Lippincott Williams and Wilkins, Australia

59. Arpitha P, Prajna NV, Srinivasan M, Muthukkaruppan V (2005) High expression of p63 combined with a large N/C ratio defines a subset of human limbal epithelial cells: implications on epithelial stem cells. Invest Ophthalmol Vis Sci 46: $3631-3636$ 